\title{
Salinity and Miscarriage: Is There a Link? Impact of Climate Change in Coastal Areas of Bangladesh - A Systematic Review
}

\author{
Sorif Hossain ${ }^{1 *}$ \\ ${ }^{1}$ Institute of Statistical Research and Training, University of Dhaka, BANGLADESH \\ *Corresponding Author: shossain9@isrt.ac.bd \\ Citation: Hossain, S. (2020). Salinity and Miscarriage: Is There a Link? Impact of Climate Change in Coastal Areas of Bangladesh - A Systematic \\ Review. European Journal of Environment and Public Health, 4(1), em0036. https://doi.org/10.29333/ejeph/6291
}

\section{ARTICLE INFO}

Received: 7 Oct. 2019

Revised: 9 Nov. 2019

Accepted: 11 Nov. 2019

\begin{abstract}
Salt is a noteworthy mineral component that plays a major role in health and infection. Unreasonable salt intake is a major reason for hypertension, cardiovascular illness, and stroke. It is assessed that 884 million individuals don't have access to clean water in the world. The expanding saltiness of characteristic drinking water sources has been accounted for as one of the numerous issues that influence low-pay nations, however one which has not been completely investigated. This problem is exaggerated by rising sea levels, climate change as well as. The developed countries are used desalination trees for reducing the salinity level, in any case, this is probably not going to be a reasonable choice for low-salary nations influenced by high saltiness like Bangladesh. Miscarriage and preeclampsia are the most widely recognized pregnancy factor with various etiological elements, including inflammatory and autoimmune conditions. All the more as of late, various investigations demonstrated that unreasonable salt intake is engaged with the advancement of inflammatory procedures through the enlistment of the Thelper-17 pathway and their inflammatory cytokines. Then again, miscarriage, preeclampsia, and adverse pregnancy outcome have been demonstrated in several studies indicated the pivotal role of inflammation in the etiology. Here, it is assumed that unreasonable salt intake during the time of pregnancy can highly be associated with increased risk of miscarriage, and adverse pregnancy outcome. Subsequently, the risk of miscarriage and adverse pregnancy status can be reduced by taking the low salt intake around the time of pregnancy status. This paper also describes the role of salt in the etiology of miscarriage and preeclampsia.
\end{abstract}

Keywords: salinity, miscarriage, coastal areas, Bangladesh

\section{INTRODUCTION}

Salt $(\mathrm{NaCl})$ is one of the effective minerals that have a significant effect on health and disease (Kotchen, Cowley, \& Frohlich, 2013). The prescribed degree of dietary salt admission is under $5 \mathrm{~g}$ (sodium $2000 \mathrm{mg}$ ) every day for adults and lower consumption in kids (Campbell et al., 2014; N.R.C. et al., 2015). Be that as it may, unnecessary dietary salt admission is a significant reason for hypertension and related sicknesses (Figure 1); including cardiovascular illness and stroke (Blaustein et al., 2012; Mozaffarian et al., 2014). Miscarriage and Preeclampsia are a common pregnancy problem. Miscarriage is characterized as the unconstrained loss of conception before the twentieth seven day stretch of pregnancy (Kalumbi, Farquharson, \& Quenby, 2005; Regan \& Rai, 2000; Taylor, Bedaiwy, \& Iwes, 2018; Toth et al., 2010). Miscarriage is classified into two categories: sporadic and recurrent. Approximately 50\% of women experience sporadic and $1 \%$ of women experience recurrent (Taylor et al., 2018). A few elements, including inflammatory and immune system issues, are engaged with the etiology of miscarriage (Taylor et al., 2018). High blood pressure, proteinuria, and kidney problems are occurring because of Preeclampsia. Around 3-5\% of women experience Preeclampsia. Preeclampsia is a significant reason for maternal mortality, maternal morbidity, and prenatal deaths (Rana, Lemoine, Granger, \& Karumanchi, 2019). Most recently studies described the role of salts in case of miscarriage and Preeclampsia. All the more as of late, studies showed that salt has a vital role in the improvement of inflammatory processes and an increase of autoimmunity (Van Der Meer \& Netea, 2013). Several studies also explain the role of the inflammatory process in the etiology of miscarriage and preeclampsia (Krementsov, Case, Hickey, \& Teuscher, 2015; Saini, Arora, Yadav, \& Bhattacharjee, 2011). This hypothesis discussed the role of salt in the etiology of miscarriage and also its impacts in Bangladeshi coastal areas.

Globally about 600 million people are dwelling in lowelevated coastal zones, those will soon be a victim of progressive salinization-due to climate change-induced sealevel rise. We know from available research that sea level may be elevated by a meter or more by the end of the twenty-first 


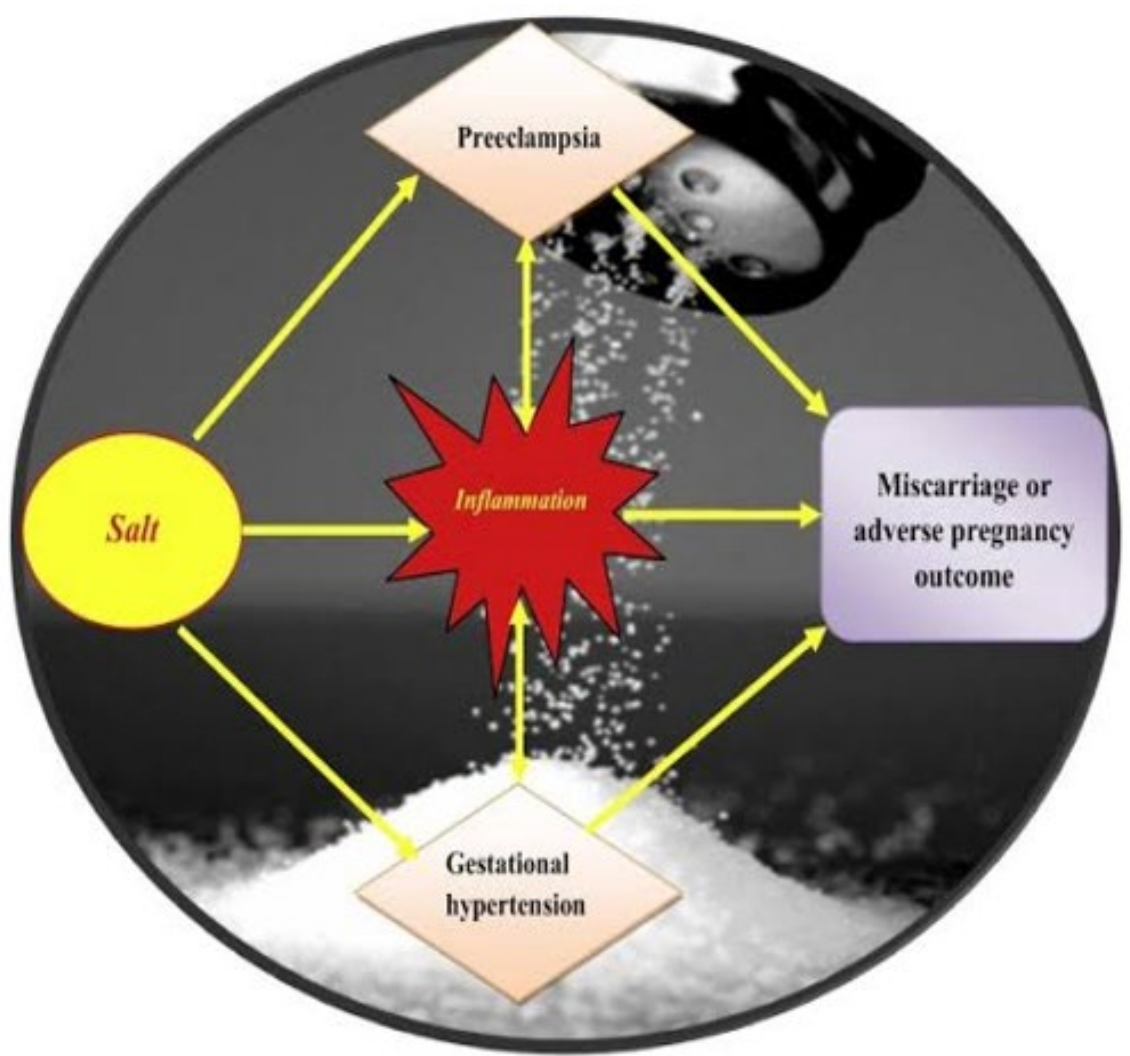

Figure 1. The association among salinity and miscarriage, preeclampsia, and Gestational hypertension

century-potentially making one billion people vulnerable. While climate change research predominantly focused on inundation and damages from surges and hurricanes, slow and steady threats like salinity from seawater intrusion could be another vital terror worth consideration. Groundwater salinity has important consequences on livelihoods and could potentially create public health hazards through its impacts on agriculture, aquaculture, infrastructure, coastal ecosystems, and the availability of fresh water for household and commercial use. Understanding the public health and economic effects of salinity intrusion may help us to know the consequences better-facilitating appropriate planning for adaptation and mitigation.

Bangladesh is one of the most climate change vulnerable countries in the world. Bangladesh is a riverine country and coastal Bangladesh is a part of the flat Ganges Delta, streaming water from the Himalayas into the Bay of Bengal. Sea-level elevation and saltwater intrusion are currently affecting about $30 \%$ of the cultivable land in the coastal Bangladesh where groundwater salinity is affected by tidal flooding, direct inundation, and mobility of saline ground and surface water (Haque, 2006). In coastal Bangladesh, primary drinking water sources like rivers, ponds (for surface water) and tube-wells (for groundwater) are threatened by saltwater intrusion from the Bay of Bengal. Approximately 20 million people living along the coastal areas are currently affected by varying degrees of salinity by drinking water obtained from various natural sources. Integrated Regional Information Networks (2007) reported high river salinity in the southern districts of Bangladesh, which has risen by $45 \%$ since 1948 . Our main objectives are to describe the consequences of salinity to the miscarriage in the coastal zones of Bangladesh.

\section{ESTIMATES OF WATER SALINITY IN BANGLADESH}

The reports by the ministry of forest in Bangladesh have included the assessment of the impacts of climate change, sealevel rise in water resources, land stability, and the health in coastal zones (Mohal et al., 2007). The sea-level rise in Bangladesh is much higher. Using the data of three coastal areas (Hiron Point, Char Changa, and Cox's Bazaar), it is shown that the sea level rise during the last 22 years in Bangladesh is higher compared to 100 years sea level rise in Global World (Mohal et al., 2007).

In Bangladesh Saltiness of surface and groundwater is dictated by a combination of elements incorporating stream, tidal floods, rainfall, and groundwater extraction, as well as the impact of sea levels and other climate factors. During the dry season (November-May), the Padma-river flows at less than a quarter of its capacity. Because of the Farakka Bridge, India, in 1975, the freshwater dropped off significantly in Padma (Mirza, 1998).

The extent of salinity in coastal areas is increased with the rising sea-levels (Vineis, Chan, \& Khan, 2011). Other elements that increase water salinity is Shrimp farming. In a previous couple of decades, enormous zones of rice fields and cultivable land in coastal areas have been converted into Shrimp farms. This has added to expanded groundwater saltiness, soil debasement, and acreage of rice (Ali, 2006). A study was undertaken to find the daily salt intake to the people of coastal areas (Khulna). The normal degree of river saltiness was evaluated at $8.21 \mathrm{~g} / \mathrm{L}$ of water in the dry season. Expecting a normal every day utilization of $2 \mathrm{~L}$ of water for each person, 
salt admission from the river water was up to $16 \mathrm{~g} /$ day (Khan, Mojumder, Kovats, \& Vineis, 2008).

\section{HEALTH IMPACTS}

Most of the people in Coastal areas of Bangladesh are exposed to salinity by drinking water. Besides drinking water, the people also exposed salinity through occupation (Shrimp farming), which affects the health of the people. The Government of Bangladesh reported the salinity exposed through drinking, bathing, occupation and as a result people suffered different health problems like hypertension, miscarriage, skin disease, and so on (Vineis et al., 2011).

The link between high dietary salt-intake with elevated blood pressure (BP) is recognized worldwide (Aburto et al., 2013). Drinking highly saline water on a regular basis could potentially also have direct and indirect impacts on health. However, the public health effect of substantial and regular sodium consumption through drinking water is a rather unexplored area of research. Even the World Health Organization (WHO) does not have any clear guidelines for safe salinity levels in drinking water, except that the testingwise unacceptable range is sodium level greater than $20 \mathrm{mg}$ per liter (WHO, 2008).

High salt intake through drinking water and resulted in hypertension could particularly be risky during pregnancy. Hypertension may cause severe pregnancy-related complications, triggering late pregnancy loss or miscarriageif not controlled. In this study, we focus on the impacts of groundwater salinity on incidents of miscarriage. A recent study (Vineis et al., 2011) established a link between high salt intakes with gestational hypertension and preeclampsia, the link between high salt intake and incidents of miscarriage is yet to explore.

\section{CONCLUSIONS}

This hypothesis offers new bits of knowledge about the role of salt in the etiology of miscarriage and preeclampsia. Risk of miscarriage is plausible for pregnant women who have high salt intake. Rising water saltiness is a further potential outcome of environmental change and ocean level ascent and furthermore raises issues of ecological equity. Not exclusively is the commitment of low-pay nations to carbon emanations frequently unimportant (as on account of Bangladesh), in any case, their weight of negative results of environmental change is absolutely lopsided. In this paper, we explained the salinity and its relation with different types of disease especially we focused on miscarriage and salinity. Accordingly, decreasing salt admission for pregnant women or women who intend to become pregnant ought to be recommended.

\section{REFERENCES}

Aburto, N. J., Ziolkovska, A., Hooper, L., Elliott, P., Cappuccio, F. P., \& Meerpohl, J. J. (2013). Effect of lower sodium intake on health: Systematic review and meta-analyses. BMJ, 346, f1326. https://doi.org/10.1136/bmj.f1326

Ali, A. M. S. (2006). Rice to shrimp: Land use/land cover changes and soil degradation in Southwestern Bangladesh. Land Use Policy, 23(4), 421-435. https://doi.org/10.1016/j.landusepol.2005.02.001

Blaustein, M. P., Leenen, F. H. H., Chen, L., Golovina, V. A., Hamlyn, J. M., Pallone, T. L., ... Gil Wier, W. (2012). How $\mathrm{naCl}$ raises blood pressure: A new paradigm for the pathogenesis of salt-dependent hypertension. American Journal of Physiology - Heart and Circulatory Physiology, 302(5), H1031-H1049. https://doi.org/10.1152/ajpheart. 00899.2011

Campbell, N. R. C., Correa-Rotter, R., Cappuccio, F., Webster, J., Lackland, D., Neal, B., \& MacGregor, G. A. (2015). Proposed nomenclature for salt intake and for reductions in dietary salt. Journal of Clinical Hypertension, 17(4), 247251. https://doi.org/10.1111/jch.12442

Campbell, N. R. C., Lackland, D. T., Chockalingam, A., Lisheng, L., Harrap, S. B., Touyz, R. M., ... Schiffrin, E. L. (2014). The international society of hypertension and world Hypertension league call on governments, nongovernmental organizations and the food industry to work to reduce dietary sodium. Journal of Hypertension, 32(2), 446-447. https://doi.org/10.1097/HJH.000000000000 0079

Haque, S. A. (2006). Salinity problems and crop production in coastal regions of Bangladesh. Pakistan Journal of Botany, 38(5), 1359-1365.

Kalumbi, C., Farquharson, R., \& Quenby, S. (2005). Miscarriage. Current Obstetrics and Gynaecology, 15(3), 206210. https://doi.org/10.1016/j.curobgyn.2005.03.004

Khan, A., Mojumder, S. K., Kovats, S., \& Vineis, P. (2008). Saline contamination of drinking water in Bangladesh. The Lancet, 371(9610), P385. https://doi.org/10.1016/S01406736(08)60197-X

Kotchen, T. A., Cowley, A. W., \& Frohlich, E. D. (2013). Salt in health and disease - A delicate balance. New England Journal of Medicine, 368, 1229-1237. https://doi.org/10.1056/NEJMra1212606

Krementsov, D. N., Case, L. K., Hickey, W. F., \& Teuscher, C. (2015). Exacerbation of autoimmune neuroinflammation by dietary sodium is genetically controlled and sex specific. FASEB Journal, 29(8), 3446-3457. https://doi.org/10.1096/ fj.15-272542

Mirza, M. M. Q. (1998). Diversion of the Ganges water at Farakka and its effects on salinity in Bangladesh. Environmental Management, 22(5), 711-722. https://doi.org/10.1007/s002679900141 
Mohal, N., \& Hossain, M. M. A. (2007). Investigating the impact of relative sea level rise on coastal communities and their livelihoods in Bangladesh. Draft Final Report. Dhaka: Institute of Water Modelling (IWM) and Center for Environmental and Geographic Information Services (CEGIS). Submitted to UK Department for Environment Food and Rural Affairs in May.

Mozaffarian, D., Fahimi, S., Singh, G. M., Micha, R., Khatibzadeh, S., Engell, R. E., ... Powles, J. (2014). Global sodium consumption and death from cardiovascular causes. New England Journal of Medicine, 371, 624-634. https://doi.org/10.1056/NEJMoa1304127

Rana, S., Lemoine, E., Granger, J., \& Karumanchi, S. A. (2019). Preeclampsia. Circulation Research, 124(7), 1094-1112. https://doi.org/10.1161/CIRCRESAHA.118.313276

Regan, L., \& Rai, R. (2000). Epidemiology and the medical causes of miscarriage. Bailliere's Best Practice and Research in Clinical Obstetrics and Gynaecology, 14(5), 839-854. https://doi.org/10.1053/beog.2000.0123
Saini, V., Arora, S., Yadav, A., \& Bhattacharjee, J. (2011). Cytokines in recurrent pregnancy loss. Clinica Chimica Acta, 412(9-10), 702-708. https://doi.org/10.1016/j.cca. 2011.01.002

Taylor, E., Bedaiwy, M., \& Iwes, M. (2018). Recurrent miscarriage. British Columbia Medical Journal.

Toth, B., Jeschke, U., Rogenhofer, N., Scholz, C., Würfel, W., Thaler, C. J. and Makrigiannakis, A. (2010). Recurrent miscarriage: current concepts in diagnosis and treatment. Journal of Reproductive Immunology, 85(1), 23-32. https://doi.org/10.1016/j.jri.2009.12.006

Van Der Meer, J. W. M., \& Netea, M. G. (2013). A salty taste to autoimmunity. New England Journal of Medicine, 368, 25202521. https://doi.org/10.1056/NEJMcibr1303292

Vineis, P., Chan, Q., \& Khan, A. (2011). Climate change impacts on water salinity and health. Journal of Epidemiology and Global Health, 1(1), 5-10. https://doi.org/10.1016/j.jegh.2011.09.001 